\title{
Study of Defects by Cathodoluminescence Measurements
}

\author{
A. Djemel ${ }^{1}$ and R-J. Tarento ${ }^{2}$ \\ ${ }^{1}$ LPCS, Université. Mentouri Constantine, \\ ${ }^{2}$ LPS, Université. Paris-Sud, Orsay, \\ ${ }^{1}$ Algeria \\ ${ }^{2}$ France
}

\section{Introduction}

Scanning electron microscopy (SEM) can be used to obtain images of a large variety of materials resulting from secondary electron. The SEM can also be used to detect different signals that provide composition information, surface morphology and characteristics of the local electronic structure. The signals provide different processes in the electron-matter interaction. The combination of different signals produces an detailled physical image and qualitative and quantitative analysis of the electronic properties of studied samples.

The cathodoluminescence (CL) is one of different signals that has frequently been used within SEM to study the semiconductor materials. This technique avoids destruction of the sample ,has a high resolution and an image depth field which are determined by the beam current, the beam energy and the beam size.

This method has been used to investigate and to identify the particular features of the crystal defects(dislocation,precipitate,boundaries (Djemel , Castaing et al ,1990); Djemel , Castaing et al ,1992).

The CL method allows the determination of quantitative information on local electronic and optical parameters of materials such as the diffusion length $(\mathrm{L})$, absorption coefficient $(\alpha)$, the dopping levels and the defects parameters such as the recombination velocity $\left(\mathrm{V}_{\mathrm{s}}\right)$, the defects density $\left(\mathrm{N}_{\mathrm{t}}\right)$, the capture cross section $(\sigma)$ and the energy level $\left(\mathrm{E}_{\mathrm{t}}\right)$ associated to defects.

The cathodoluminescence is based on the study of the interaction of the electron beam with the semiconductor. This interaction gives rise to electron-hole (e-h) pairs generation within the sample. The density of e-h pairs generated is limited by the scattering process of the electron beam within the sample. The distribution of the e-h pairs created depends on the diffusion length and the recombination behaviour at the surface and in the bulk. The recombination can be either radiative in which case a photon is emitted or non-radiative generating phonons, Auger electron ....At the surface ,the recombination process is generally non-radiative. The generated photon submits to an absoption in the escape from the sample and those that finally emerge can be collected and subsequently detected to provide the cathodoluminescence signal. The radiative recombination results from band to 
band transition and band to energy level transition. The energy level is associated with impurities or with crystal defects.

\section{Quantitative study}

The quatitative determination of CL requires an accurate simulation of the CL signal as a function of the electron beam paramaters, the beam current $\left(\mathrm{I}_{\mathrm{p}}\right)$ and energy beam $\left(\mathrm{E}_{0}\right)$. However, this depends on various stages :

- $\quad$ a better description of the electron-semiconductor interaction

- the diffusion and the distribution of the generated (e-h) pairs within the sample

- the boundary conditions and the recombination at the surface and in the bulk.

\subsection{Generation function}

Many models can describe the electron-semiconductor interaction : the polynomial form (Everhoff\&Hoff,1971) , the point or spherical models , the modified Gaussian approximation (Wu \& Wittry,1978 ; Hergert, Reck et al,1987 ) and the Monte Carlo method (Phang, Pey et al ,1992).

For GaAs, the electron-semiconductor interaction is approximeted by the modified Gaussian function which gives the local generation rate $G(z)$

$$
\begin{gathered}
\mathrm{G}(\mathrm{z})=(\mathrm{\rho} / \mathrm{R}) \varphi(\mathrm{u}) \\
\varphi(\mathrm{u})=\mathrm{A} \exp \left[-\left(\mathrm{u}-\mathrm{u}_{0}\right)^{2} / \Delta \mathrm{u}\right]-\mathrm{B} \exp -\left(\mathrm{bu} / \mathrm{u}_{0}\right)
\end{gathered}
$$

where $u=\rho z / R, \rho$ is the density of semiconductor $\left(\mathrm{g} / \mathrm{cm}^{3}\right), z$ is the depth $(\mathrm{cm})$ and $R$ is the maximum electron range $\left(\mathrm{g} / \mathrm{cm}^{2}\right) \cdot \mathrm{R}$ has been deduced for $\mathrm{GaAs}$ as e function of the beam energy $\mathrm{E}_{0}(\mathrm{keV})$ :

$$
\mathrm{R}=2.56 .10^{-3}\left(\mathrm{E}_{0} / 30\right)^{1.7}
$$

For GaAs , $\mathrm{u}_{0}=0.125, \Delta \mathrm{u}=0.350, \mathrm{~b}=4.0, \mathrm{~B} / \mathrm{A}=0.4$. The constant $\mathrm{A}$ and $\mathrm{B}$ are determined using the normalization condition.( Wu \& Wittry,1978).

\subsection{Diffusion and distribution}

Consider a n-type semiconductor doped with concentration $\mathrm{N}_{d}$.

The transport of (e-h) pairs generated has been controlled by the continuity equation which has the following classic form :

$$
\operatorname{div} J=G(z)-r(z)
$$

where $\mathrm{J}$ is the flux of the carrier excess, $\mathrm{r}(\mathrm{z})$ is the recombination rate in the bulk and at the semiconductor surface.

The recombination rate in the bulk (neutral region) is expressed by:

$$
\mathrm{r}(\mathrm{z})=\Delta \mathrm{p}(\mathrm{z}) / \tau_{\mathrm{p}}
$$


where $\Delta \mathrm{p}(\mathrm{z})$ is the excess hole carrier and $\mathrm{\tau}_{\mathrm{p}}$ is the hole lifetime .

In the litterature there are two definitions of the semiconductor surface. In the first definition, the surface is defined as a dead-layer (non-radiative region ) with a thickness $\mathrm{Z}_{\mathrm{T}}$ ( Hergert, Reck et al 1987 ; Wittry \& Kyser 1967 ).

The distribution of minority excess carriers is determined by the continuity equation in the bulk or neutral region:

$$
\mathrm{D}_{\mathrm{p})} \mathrm{d}^{2} \Delta \mathrm{p}(\mathrm{z}) / \mathrm{dz} \mathrm{z}^{2}=\mathrm{G}(\mathrm{z})-\Delta \mathrm{p}(\mathrm{z}) / \tau_{\mathrm{p}}
$$

In the second definition, the surface is described by a defects density $\mathrm{N}_{t}$ and an energy level $E_{t}$ in the band gap ( Djemel, Tarento et al , 1998 ).The consequence of electronic surface states associated to surface defects consists in the existence of a depletion region that is linked to a potential barrier $E_{b}$ between the free semiconductor surface and the bulk.This second definition of surface is used in cases of dislocation ( Tarento \& Marfaing , 1992 ) and grain boundary ( Oualid, Singal et al , 1984 ).

The distribution of excess carrier is governed by :

- the continuity equations of both excess majority and minority carrier in the depletion region ( the recombination is neglected in the region $r(z)=0$ ) (Djemel, Tarento et al $, 1998)$ :

$$
\begin{aligned}
& -d^{2} \Delta \mathrm{n}(\mathrm{z}) / \mathrm{dz} \mathrm{z}^{2}+2 \mathrm{a}\left(\mathrm{z}-\mathrm{Z}_{\mathrm{d}}\right) \mathrm{d} \Delta \mathrm{n}(\mathrm{z}) / \mathrm{dz}+2 \mathrm{a} \Delta \mathrm{n}(\mathrm{z})=\mathrm{G}(\mathrm{z}) / \mathrm{D}_{\mathrm{n}} \\
& -\mathrm{d}^{2} \Delta \mathrm{p}(\mathrm{z}) / \mathrm{dz^{2 }}-2 \mathrm{a}\left(\mathrm{z}-\mathrm{Z}_{\mathrm{d}}\right) \mathrm{d} \Delta \mathrm{p}(\mathrm{z}) / \mathrm{dz}-2 \mathrm{a} \Delta \mathrm{p}(\mathrm{z})=\mathrm{G}(\mathrm{z}) / \mathrm{D}_{\mathrm{p}}
\end{aligned}
$$

Using the Einstein relation $(\mathrm{D} / \mu=\mathrm{kT} / \mathrm{e})$, a becomes equal to $\mathrm{N}_{\mathrm{d}} \mathrm{e}^{2} / 2 \mathrm{kT} \varepsilon, \mathrm{D}$ and $\mu$ are the diffusion coefficient and mobility of carriers and $\varepsilon$ is the electric permitivity.

- $\quad$ and by the continuity equation of excess minority carrier in the neutral region (in the bulk)

$$
\mathrm{D}_{\mathrm{p}} \mathrm{d}^{2} \Delta \mathrm{p}(\mathrm{z}) / \mathrm{dz} \mathrm{z}^{2}=\mathrm{G}(\mathrm{z})-\Delta \mathrm{p}(\mathrm{z}) / \tau_{\mathrm{p}}
$$

\subsection{Surface recombination}

The recombination rate at the semiconductor surface is treated by two methods. The free surface of semiconductor is defined as a dead-layer (non-radiative region) with a thickness $Z_{\mathrm{T}}$ and a surface recombination velocity $\mathrm{V}_{\mathrm{S}}$ ( Hergert, Reck et al , 1987 ; Wittry \& Kyser , 1967 ). In this case $V_{S}$ is found from the condition:

$$
\mathrm{D}_{\mathrm{p}}[\mathrm{d} \Delta \mathrm{p}(\mathrm{z}) / \mathrm{dz}]_{\mathrm{z}=0}=\mathrm{V}_{\mathrm{S}} \Delta \mathrm{p}(0)
$$

In the second method, the free surface of semiconductor is described by defects density $\mathrm{N}_{t}$ and an energy level $E_{t}$ in the band gap with an occupation probability $f$ given by the Shockley-Read-Hall theory.

$$
\mathrm{f}=\left[\Delta \mathrm{n}(0)+\mathrm{n}_{0}+\mathrm{n}_{\mathrm{i}} \exp \left(\left(\mathrm{E}_{\mathrm{i}}-\mathrm{E}_{\mathrm{t}}\right) / \mathrm{kT}\right)\right] /\left[\Delta \mathrm{n}(0)+\mathrm{n}_{0}+\Delta \mathrm{p}(0)+\mathrm{p}_{0}+2 \mathrm{n}_{\mathrm{i}} \cosh \left(\left(\mathrm{E}_{\mathrm{t}}-\mathrm{E}_{\mathrm{i}}\right) / \mathrm{kT}\right)\right]
$$

$\mathrm{n}_{0}, \mathrm{n}_{\mathrm{i}}, \mathrm{p}_{0}, \mathrm{E}_{\mathrm{i}}$ are defined in (Djemel , Nouiri et al ,2002 ). 
$\Delta \mathrm{n}(0), \Delta \mathrm{p}(0)$ are the excess carriers at the surface $(\mathrm{z}=0)$ of the electron and hole respectively.

The recombination rate $\mathrm{U}(0)$ at the surface $(\mathrm{z}=0)$ is given by:

$$
\mathrm{U}(0)=C \mathrm{~N}_{\mathrm{t}}\left(\Delta \mathrm{n}(0) \Delta \mathrm{p}(0)+\mathrm{p}_{0} \Delta \mathrm{n}(0)+\mathrm{n}_{0} \Delta \mathrm{p}(0)\right) /\left(\mathrm{n}_{\mathrm{t}}+\mathrm{n}_{0}+\Delta \mathrm{n}(0)+\mathrm{p}_{\mathrm{t}}+\mathrm{p}_{0}+\Delta \mathrm{p}(0)\right)
$$

Where $\mathrm{C}=\sigma \mathrm{V}_{\text {th }}$ is the capture coefficient of electron and hole ( $\sigma$ is the capture cross section which is generally linked to both defect and the environment (Bourgoin \& Corbett 1972), and $V_{\text {th }}$ is the thermal velocity ).

$\mathrm{n}_{\mathrm{t}}, \mathrm{p}_{\mathrm{t}}$, are given in Ref ( Djemel, Nouiri et al , 2004 ).

The relation between $V_{S}$ (first definition of surface) and $\left(N_{t}, E_{t}\right)$ (second definition of surface) can be established ( Djemel, Nouiri et al , 2002 ).

\subsection{Signal of Cathodoluminescence (CL)}

The CL signal is calculated from the excess minority carrier in the neutral region (in the bulk).The photons are generated within the sample when the carriers recombine radiatively. It is assumed that the CL signal is proportional to the integral of the carriers excess over the generation volume. The main optical loss mechanism taken into account is the absorption within the sample. The attenuation of photons propagation towards the surface is given by an exponential law.

In the case where the suface is considered as a dead-layer with a thickness $Z_{T}$, the CL signal is given by: ( Hergert , Hildebrandt et al , 1987 ; Hildebrandt , Schreiber et al ,1988 ).

$$
\begin{gathered}
\mathrm{I}_{\mathrm{CL}} \alpha \int\left(1 / \tau_{\mathrm{r}}\right) \sin \theta_{\mathrm{c}} \mathrm{F}\left(\alpha_{\mathrm{c}}\right) \mathrm{d} \theta ; \alpha_{\mathrm{c}}=\alpha / \cos \theta \\
\mathrm{F}(\mathrm{x})=\tau_{\mathrm{\tau}} \mathrm{G}_{0} \exp \left(-\alpha \mathrm{Z}_{\mathrm{T}}\right)\left[\varphi\left(\mathrm{x}, \mathrm{Z}_{\mathrm{T}}\right)-(\mathrm{Lx}+\mathrm{S}) \varphi\left(1 / \mathrm{L}, \mathrm{Z}_{\mathrm{T}}\right) /(1+\mathrm{S})\right] /\left(1-\mathrm{x}^{2} \mathrm{~L}^{2}\right) \\
\varphi\left(\mathrm{x}, \mathrm{Z}_{\mathrm{T}}\right)=\int \exp (-\alpha \mathrm{z}) \mathrm{G}\left(\mathrm{z}+\mathrm{Z}_{\mathrm{T}}\right) \mathrm{dz}
\end{gathered}
$$

where $\theta_{c}$ denote the critical angle of the total reflexion at the surface, $G_{0}$ is the total generation rate, $\tau$ and $\tau_{r}$ are the total and radiative lifetimes, respectively, $L$ is the diffusion length , $\alpha$ is the optical absorption coefficient, $\mathrm{S}$ is the reduced surface recombination velocity.

In the second definition where the surface is described by defects density $\mathrm{N}_{t}$ and an energy level $E_{t}$ in the band gap ,the CL signal is written as follow (Djemel , Kouissa et al , 2008 )

$$
\mathrm{I}_{\mathrm{CL}} \alpha \int\left[\Delta \mathrm{p}(\mathrm{z}) / \tau_{\mathrm{p}}\right] \exp \left(-\alpha_{\mathrm{b}} \mathrm{z}\right) \eta \mathrm{dz}
$$

$\tau_{p}$ is the lifetime of excess minority carriers, $\alpha_{b}$ is the optical absorption coefficient that depends on the wavelength, $\eta$ is the efficiency of radiative recombination and written as (Yacobi \& Holt , 1990 ) :

$$
\eta=\tau_{\mathrm{nr}} /\left(\tau_{\mathrm{r}}+\tau_{\mathrm{nr}}\right)
$$

$\tau_{r}$ and $\tau_{n r}$ are the lifetimes of radiative and non-radiative recombination, respectively . $\Delta p(z)$ is the minority carriers excess solution of equations (7), (8) and (9). 


$$
\begin{aligned}
& \Delta \mathrm{p}(\mathrm{z})=\mathrm{B}_{\mathrm{p}} \exp \left[-\left(\mathrm{z}-\mathrm{Z}_{\mathrm{d}}\right) / \mathrm{L}_{\mathrm{p}}\right]+ \\
& +\mathrm{L}_{\mathrm{p}} / 2 \mathrm{D}_{\mathrm{p}} \int \mathrm{G}(\mathrm{z})\left\{\exp \left(-\left|\mathrm{z}-\mathrm{Z}_{\mathrm{d}}\right| / \mathrm{L}_{\mathrm{p}}\right)-\exp \left[-\left(\mathrm{z}+\mathrm{z}^{\prime}-2 \mathrm{Z}_{\mathrm{d}}\right) / \mathrm{L}_{\mathrm{p}}\right]\right\} \mathrm{dz}
\end{aligned}
$$

$\mathrm{B}_{\mathrm{p}}=\Delta \mathrm{p}\left(\mathrm{z}=\mathrm{Z}_{\mathrm{d}}\right)$ is a constant and represents the excess carrier at the limit between neutral region and depletion region .

The influence of parameters of electron beam (beam intensity $I_{p}$ and energy beam $E_{0}$ ), of parameters of semiconductor $\left(\mathrm{N}_{\mathrm{d}}, \mathrm{L}_{\mathrm{p}}, \alpha_{\mathrm{b}}\right)$ and of parameters of surface $\left(\mathrm{V}_{\mathrm{s}}, \mathrm{Z}_{\mathrm{T}}\right)$ or $\left(\mathrm{N}_{\mathrm{t}}\right.$, Et, $\sigma$ ) on the CL signal has been intensively studied ( Wittry \& Kyser , 1967 ; Djemel , Nouiri et al ; 2002;Ben Nacer,Matoussi et al ,2009).

On the other hand,there are correlations between the theoretical CL signal and CL measurement to determine the parameters of surface $\left(\mathrm{V}_{\mathrm{s}}, \mathrm{Z}_{\mathrm{T}}\right.$ ) ( Hergert, Reck et al , 1987) or $\left(\mathrm{N}_{\mathrm{t}}, \mathrm{Et}, \mathrm{\sigma}\right)$ ( Djemel , Nouiri et al , 2000 ).

To illustrate the CL calculation where the surface is defined by $N_{t}, E_{t}$ and $\sigma$, one sample of p-type GaAs is investigated experimentally. The p-type conduction is obtained by thermal treatment of semi-insulating GaAs (heated at $1019{ }^{\circ} \mathrm{C}, 24 \mathrm{~h}$ ), the acceptors concentration $\mathrm{Na}=10^{16} \mathrm{~cm}^{-3}$ has been measured by Hall effect (Djemel, Castaing et al , 1992 ).

Two surfaces are compared: one is non-treated and the other is chemically polished with $\mathrm{H}_{2} \mathrm{SO}_{4}: \mathrm{H}_{2} \mathrm{O}_{2}: \mathrm{H}_{2} \mathrm{O}$ (9:1:1) . CL measurements have been performed at room temperature. The primary electron beam intensity is $15 \mathrm{nA}$, with an electron energy ranging from 5 to $40 \mathrm{KeV}$.

To understand the influence of $E_{t}$ on the CL intensity, we have reported in figure 1, the variation of the occupation probability $f$ (equation 11) as a function of $\mathrm{E}_{\mathrm{t}}$ for different excess carrier at the surface $\Delta \mathrm{n}(0)$. This figure shows that $f$ increases when the energy level $\mathrm{E}_{\mathrm{t}}$ moves away from the conduction band $E_{c}$; it means that the number of the occupied centres is increased, consequently, the surface recombination velocity increases. Therefore, the change in energy level $E_{t}$ explains the surface recombination. On the other hand, the variation of $f$ is important when the excess carrier at the surface $\Delta \mathrm{n}(0)$ increases.

Figure 2 shows the CL curves (equation 16) for different $E_{t}$. The influence of $E_{t}$ on the CL curves is important for the low electron beam energy. The CL intensity increases and the maximum moves to low acceleration energy when $E_{t}$ is near to conduction band (weak surface recombination). This behaviour is similar to that of the surface recombination velocity (Hergert, Reck et al, 1987) .

In figure 3, the CL intensity is measured for two surface states. After chemical treatment of the surface (open circles), the CL intensity increases in the low electron energy region .In the high electron energy region, the difference of CL signal between both surface states (treated and non-treated chemically) is reduced...

The adjustment between the numerical results and experimental data has been obtained by a change in energy level $E_{t}$. Thus, the two surface states can be characterised by a same defect density $\mathrm{N}_{\mathrm{t}}=2.10^{9} \mathrm{~cm}^{-2}$, and an energy level $\mathrm{E}_{\mathrm{t}}=1.30 \mathrm{eV}$ (Fig.3, 1), and by an energy level $\mathrm{E}_{\mathrm{t}}=1.33 \mathrm{eV}$ (Fig.3, 2). The similar surface states are obtained in $\mathrm{p}-\mathrm{GaAs}$ deformed and non-deformed (Djemel, Nouiri et al, 2000). 


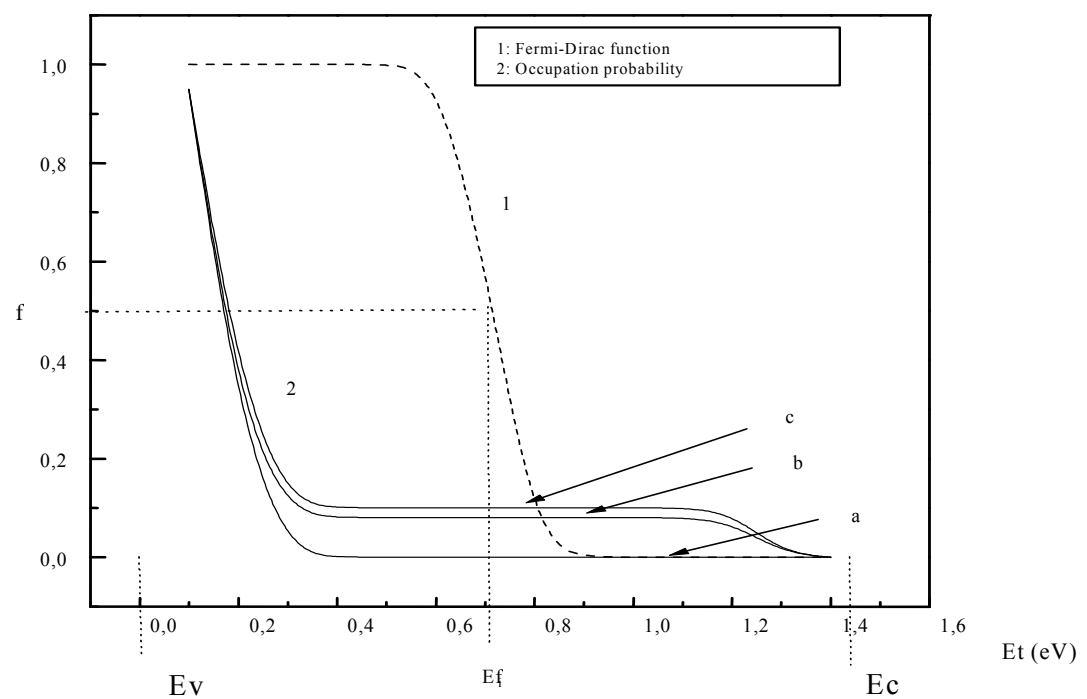

Fig. 1. The occupation probability $f$ as a function of $\mathrm{E}_{\mathrm{t}}$ for different excess carrier at the surface $\left(\Delta \mathrm{n}(0)=10^{12} \mathrm{~cm}^{-3}(\mathrm{a}), 10^{13} \mathrm{~cm}^{-3}(\mathrm{~b}), 10^{14} \mathrm{~cm}^{-3}(\mathrm{c})\right)$

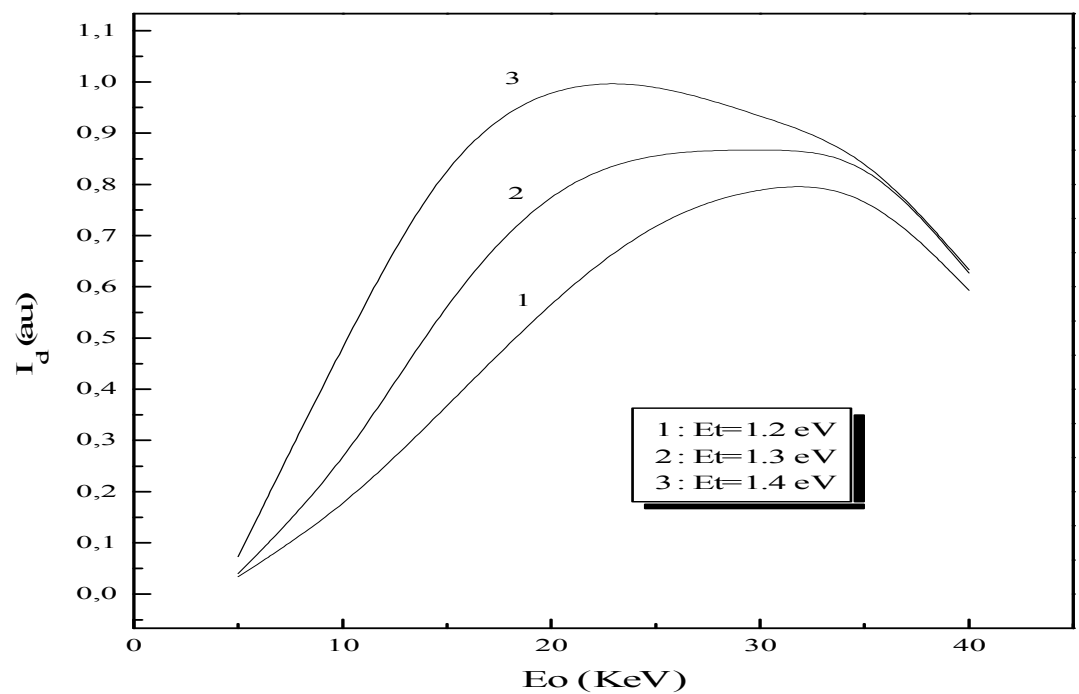

Fig. 2. CL intensity as a function of electron beam energy for different $E_{t}$. 


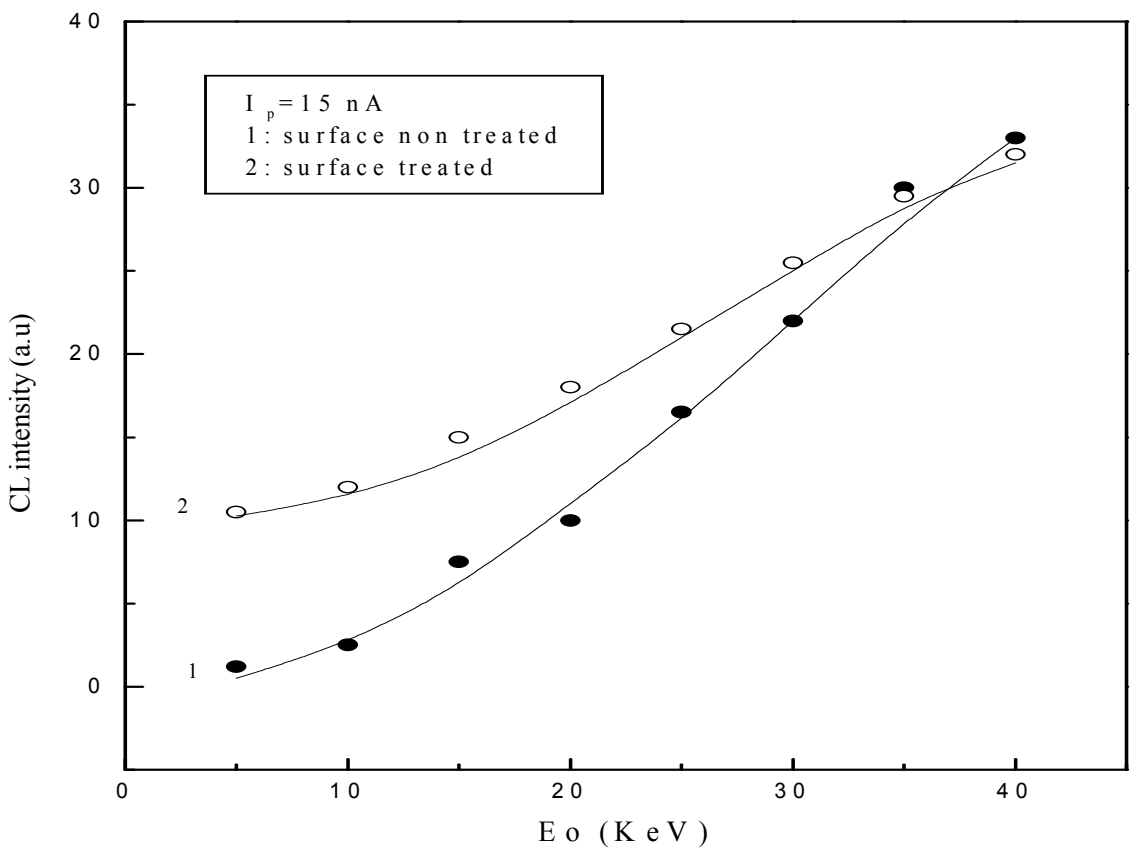

Fig. 3. CL intensity as a function of electron beam energy $E_{0}$ before and after surface treatment for p-GaAs. Full lines are the results of proposed model (Djemel, Tarento et al, 1998).

\section{Electrical activity of defects}

The electrical activity of defects can be imaged by cathodoluminescence .It reveals the regions where the recombination is radiative or non radiative. This electrical activity can be observed by the measurement of the contrast $\left(\mathrm{C}_{N R}\right)$ which is defined by the relative difference between the measured CL intensity over the defect and the measured CL intensity in the region without defect. The contrast is changed by the modification of the electronic properties of defects which are induced by the external treatment (hydrogenation, thermal treatment.. (Djemel , Castaing et al ,1990 ;Djemel , Castaing et al ,1992).

Figure 4 illustreates the modifications of the thermal treatment on the electrical activity of defects in GaAs. 


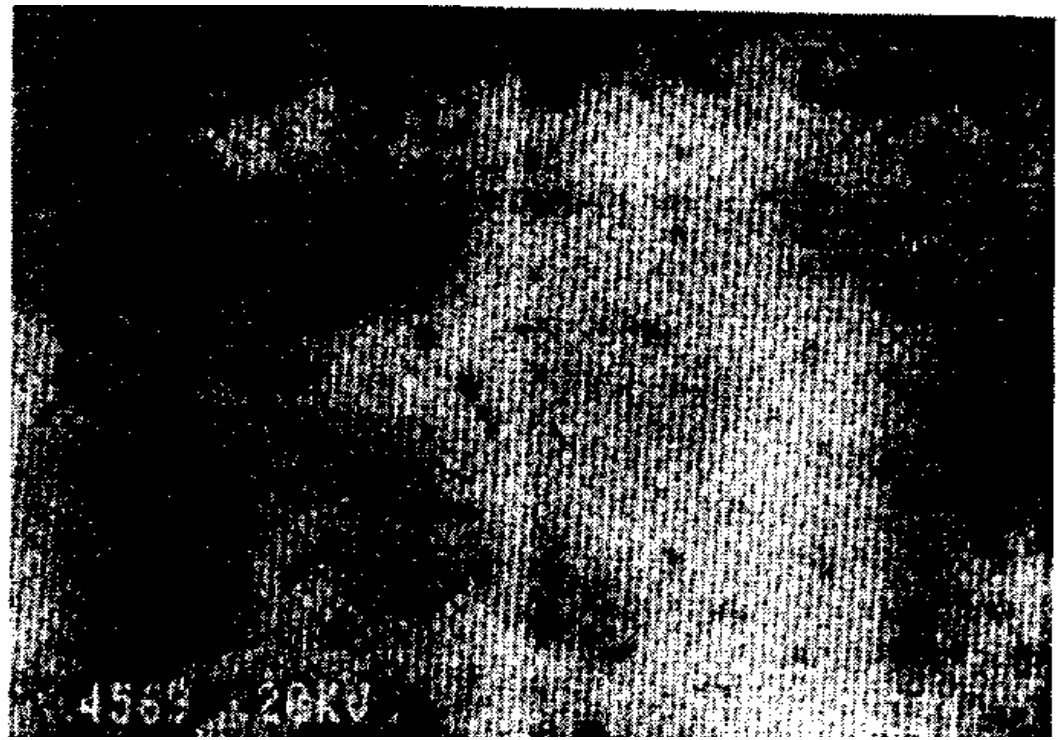

Fig. 4. CL observation after a thermal treatment of 15 hours at $850^{\circ} \mathrm{C}$ followed by quenching, with $\mathrm{Si}_{3} \mathrm{~N}_{4}$ encapsulation ( Djemel , Castaing et al ,1990 )(x 1000)

Two kinds of contrast are essentially observed : dark contrast or halo contrast such as illustrated in fig.5 and white contrast. The two kinds of contrast are explained (i) by the existence of non radiative recombination centres or energy elimination by any other process ( phonons , Auger ...) ( or ones emitting out of the spectral band of detector ) for the dark contrast and (ii) by the existence of radiative recombination centres or by an increase of carrier concentration for the white contrast .
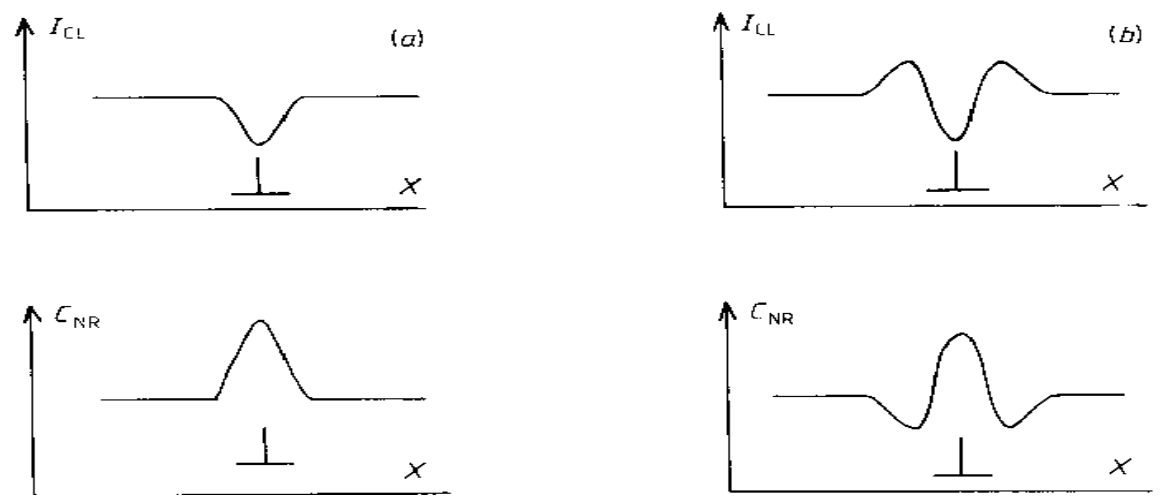

Fig. 5. Typical variation of CL Intensity $\left(\mathrm{I}_{\mathrm{CL}}\right)$ for a line scan through a defect and variation of contrast $\left(\mathrm{C}_{\mathrm{NR}}\right)$ : a) dark contrast , b) halo contrast. ( Djemel , Castaing et al ,1990)

Figure 6 illustreates the modifications of the hydrogenation on the electrical activity of subgrain boundaries in GaAs. 

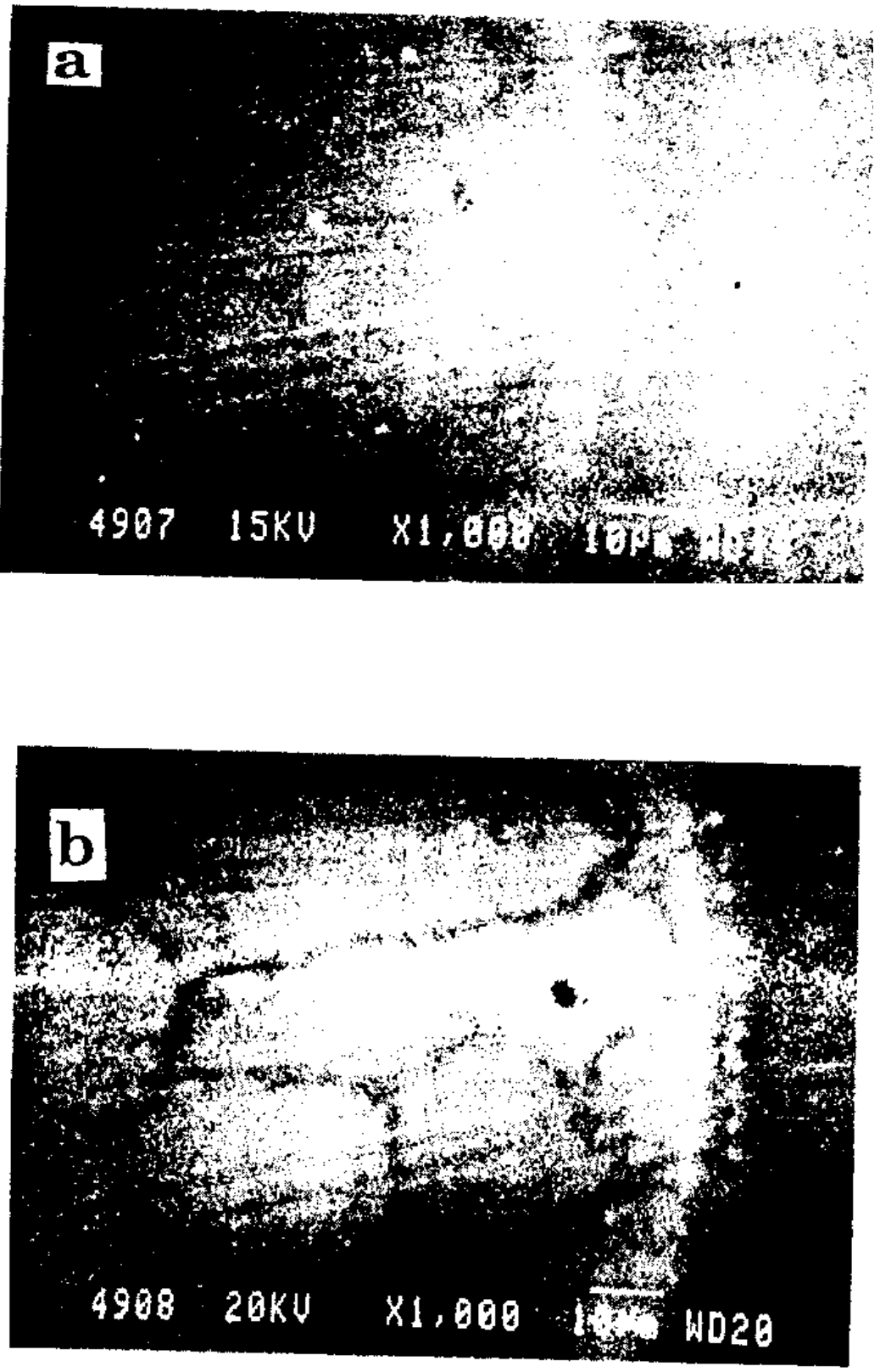


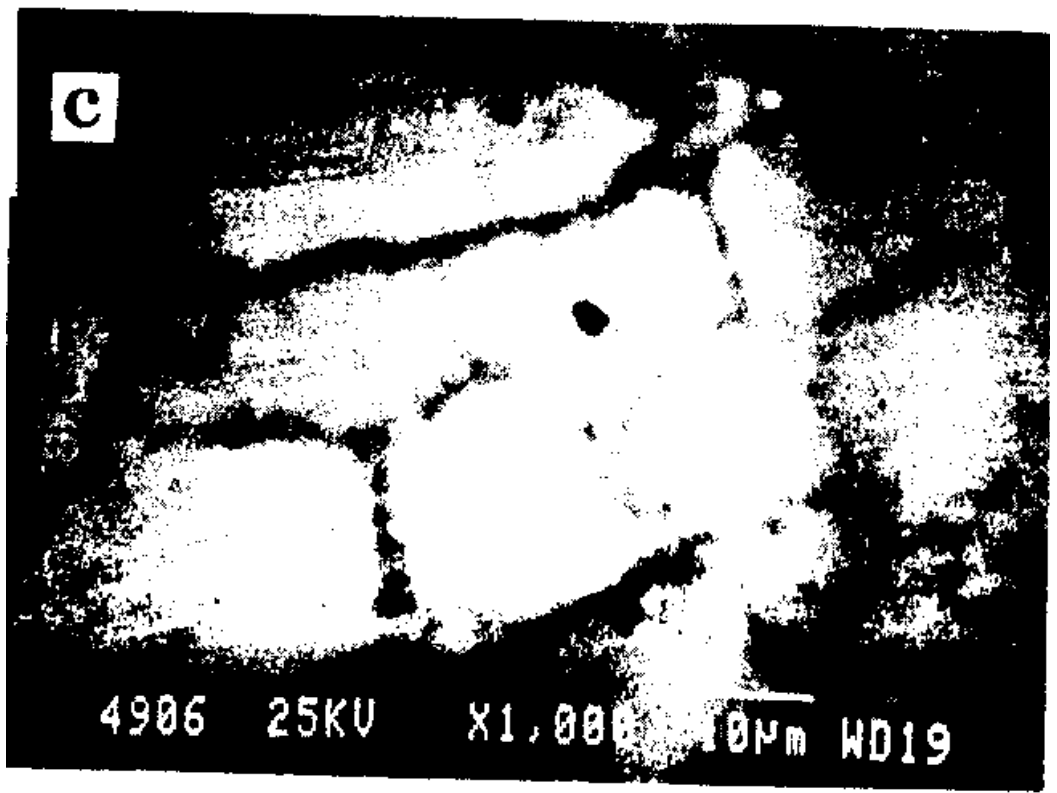

Fig. 6. CL migrographs of deformed GaAs covered with a layer of GaAlAs and exposed to a hydrogen plasma. Observations for various beam accelerating voltages: a) $15 \mathrm{KeV}$, b) 20 $\mathrm{KeV}$, c) $25 \mathrm{KeV}$.( Djemel, Castaing et al ,1992)

Deuterium is introduced in deformed GaAs by RF plasma and the Deuterium profil is determined by secondary ion mass analysis (SIMS).We have checked that the CL emission originates from the subsurface region containing Deuterium, by changing the range penetration of electrons. The values are $1.6 \mu \mathrm{m}, 2.6 \mu \mathrm{m}, 3.7 \mu \mathrm{m}$ for $15 \mathrm{KeV}, 20 \mathrm{KeV}$, and $25 \mathrm{KeV}$ beam voltages respectively.The subgrain boudaries are invisible at the low beam voltage (Fig.6c) when electron-hole pairs are generated in the Hydrogenated region of the specimen (1-2 $\mu \mathrm{m}$ obtained by the Deuteurium profil SIMS). For high voltages, the contrast is strong (Fig.6c) because the hydrogen penetration is small compared to the electrons one.

\section{Spectroscopic study}

Defects and Complex defects in semiconductors are still attractive topics.They influence the electronic and optical properties of the materials. Complex defects are formed between the defects impurities(doping,already present in the starting material) and the created intrinsic defects (vacancy,interstitial and substitution position, anti-site).These defects include nearest- and second-neighbor point-defect pairs. These defects and complex defects introduce generally the energy levels in the band gap. They can be radiative or nonradiative. In the case of radiative defects, the cathodoluminescence (Yacobi,Holt,1986;Lei,Leipner et al ,2004) and the photoluminescence (Sauncy,Palsule et al,1996;William,1968) allow to obtain a quantitative spectroscopy of the energy levels associated with defects. 
Figure 7 shows the liquid-He spectra in semi-insulating GaAs. (Yacobi, Holt,1986)

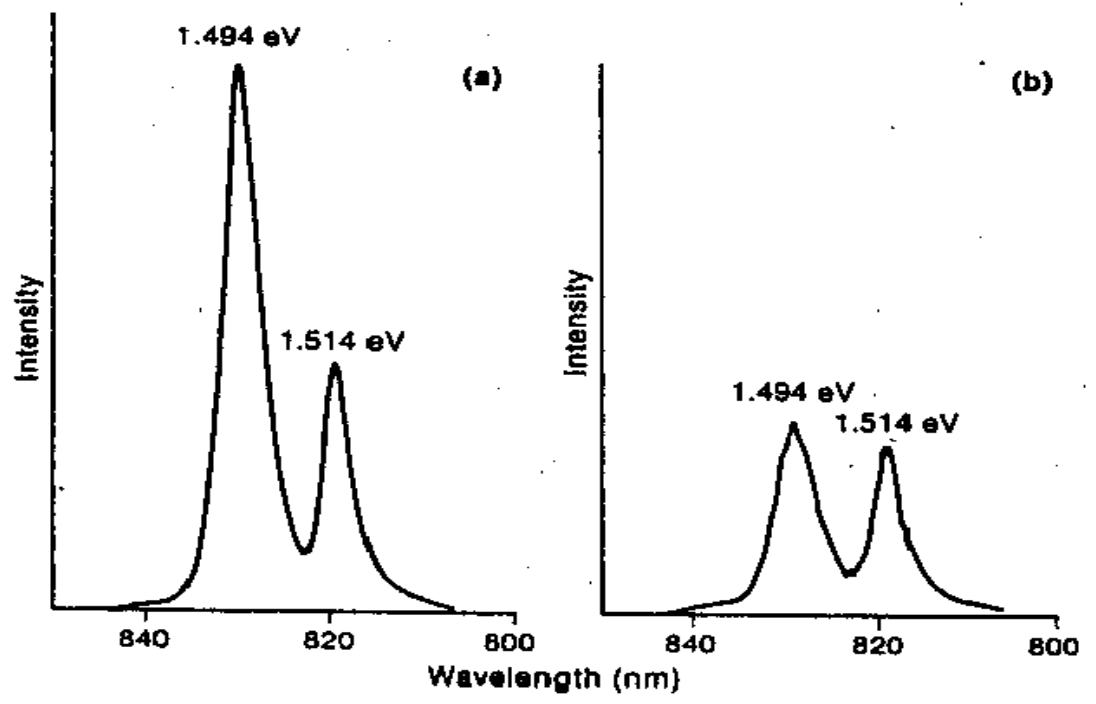

Fig. 7. Liquid-He CL spectra from (a) bright area and (b) an adjacent dark area (Fig.8) in semi-insulating GaAs (Yacobi, Holt, 1986)

Using the monochromatic CL micrograph, we can determine the spatial distribution of the defect corresponding to the emission .Fig.8.

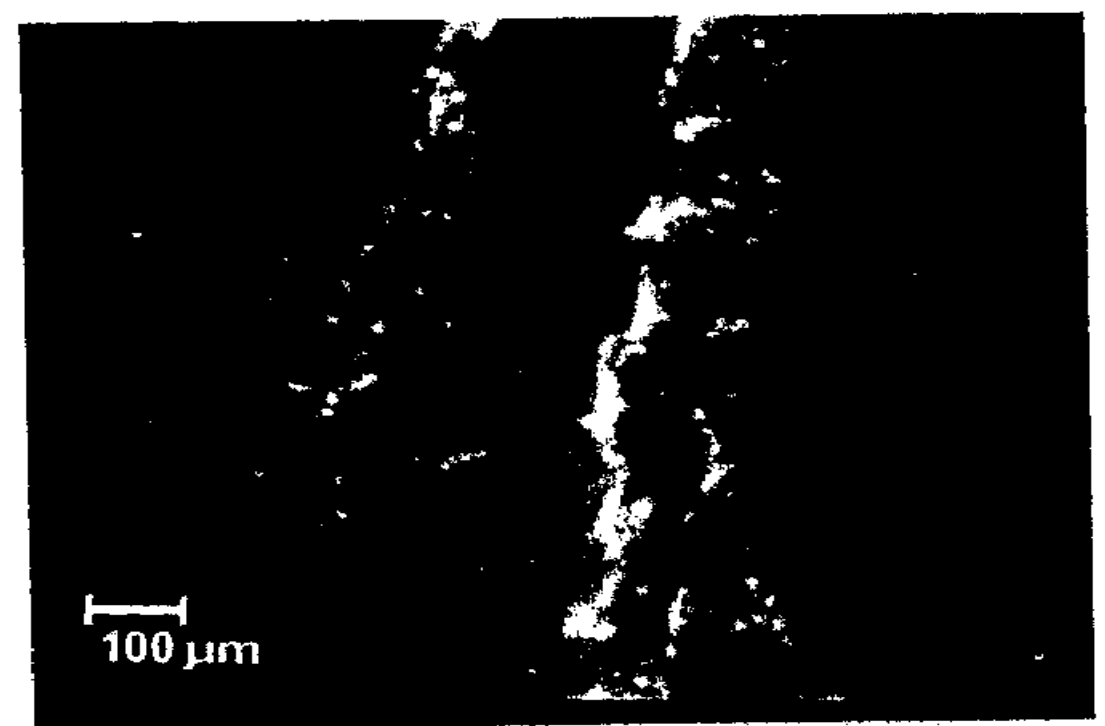

Fig. 8. Liquid-He monochromatic CL micrograph of a cell boundary in semi-insulating GaAs using the $1.494 \mathrm{eV}$ emission due to residual Carbon (Yacobi, Holt, 1986) 


\section{Impact of electron beam irradiation}

The cathodoluminescence is an effective technique for the analysis of the electronic properties of semiconductors. However, some materials ( $\mathrm{GaAs}, \mathrm{ZnO}, \mathrm{GaN}$..) are sensitive to the irradiation electron beam (Djemel, 1988 ; Dierre,Yuan et al ,2008). This sensibility is shown by a decrease of the CL intensity (increase of contrast) or an increase of CL intensity. The variation of CL intensity depends on the chemical nature of surface (Ga face, As face, $\mathrm{Zn}$ face , $\mathrm{O}$ face , $\mathrm{N}$ face )(Dierre,Yuan et al ,2008) , on the emission band ( energy level in the gap band) (Dierre,Yuan et al, 2008) and on the external treatment supported by the materials (Djemel, 1988) .

Figures 9 and 10 illustrate the impact of electron beam irradiation before and after the treatment by hydrogen (Djemel, 1988).

Different mechanisms are induced by the electron beam. The electron beam irradiation induces an Electron Stimulated Reaction (Bourgoin, Corbett, 1972).The incident electrons depose locally a large energy which causes the bond breaking in the materials and the formation of the reactive sites. These reactive sites can react with the defects from surface or in the bulk. The electron beam, across the locally deposited energy, can enhance the migration of mobile defects and impurities. The interaction, between all defects and the complex defect responsible of luminescence, changes the electronic environment of the last defect.Thus, these defects can turn into radiative and nonradioactive recombination centres

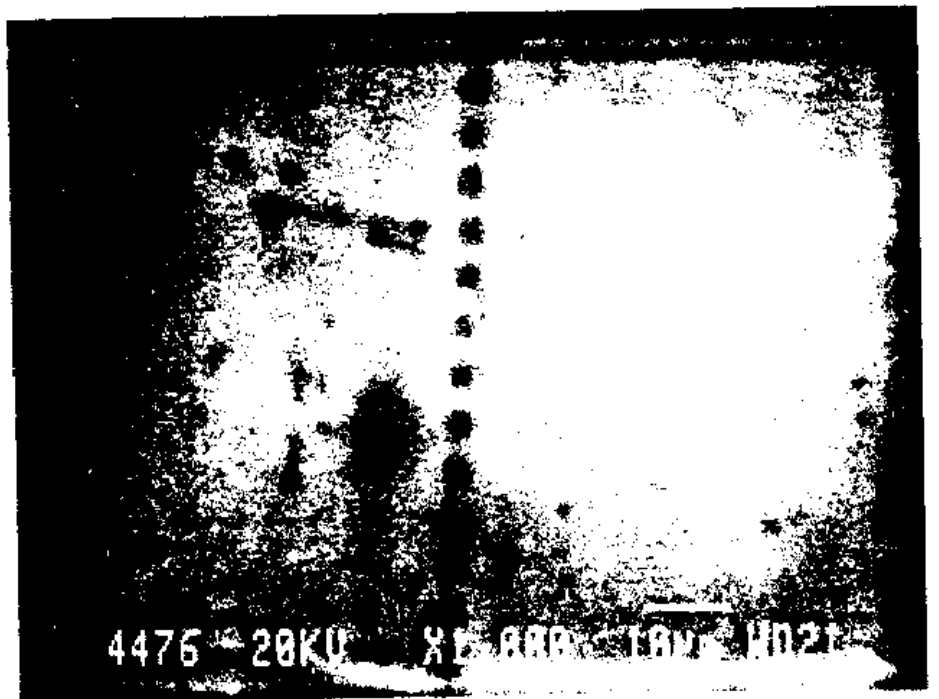

Fig. 9. Impact of electron beam irradiation observed by CL in GaAs before hydrogenation (dark dots) (Djemel, 1988) 


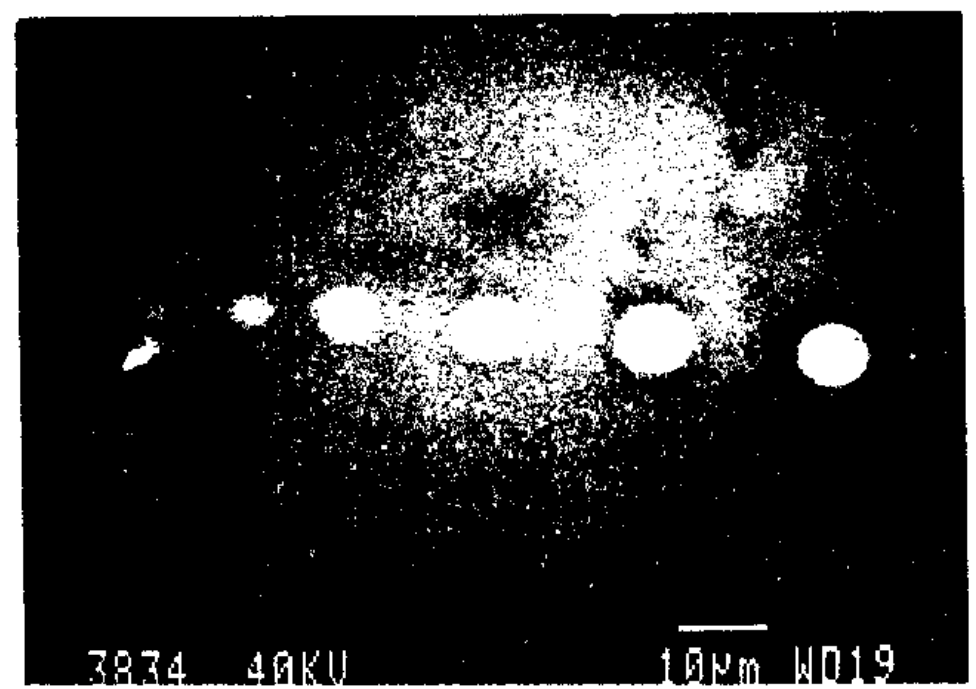

Fig. 10. Impact of electron beam irradiation observed by CL in GaAs after hydrogenation (white dots ) (Djemel,1988)

Different mechanisms are induced by the electron beam. The electron beam irradiation induces an Electron Stimulated Reaction (Bourgoin, Corbett, 1972).The incident electrons depose locally a large energy which causes the bond breaking in the materials and the formation of the reactive sites. These reactive sites can react with the defects from surface or in the bulk. The electron beam, across the locally deposited energy, can enhance the migration of mobile defects and impurities. The interaction, between all defects and the complex defect responsible of luminescence, changes the electronic environment of the last defect.Thus, these defects can turn into radiative and nonradioactive recombination centres.

\section{Effect of temperature on $\mathrm{CL}$ intensity}

Few theoretical and experimental works on the variation of the CL intensity as a function of the temperature have been realized (Jones, Nag et al, 1973; Lei, Leipner et al, 2004; Djemel, Kouissa et al ,2009). These studies concern the temperature variation of CL intensity for the transition conduction band and valence band (Jones, Nag et al, 1973 ). In this work a large discrepancy exists between the theoretical calculation and the experimntal data. Lei,Leipner et al ,2004 have studied the temperature variation of the luminescence bands for n-GaAs in the temperature range $20 \mathrm{~K}-100 \mathrm{~K}$ (Lei,Leipner et al , 2004). A new theoretical study on the CL intensity as a function of temperature and taking into account the influence of temperature on all physical parameters is done by Djemel,Kouissa et al ,2009 . Using this model, an improvement in the fitting of experimental data(Lei,Leipner et al , 2004 ) is shown in (Fig.11) allowing an estimation of capture cross section and the determination of the parameter of the radiative recombination centre. 


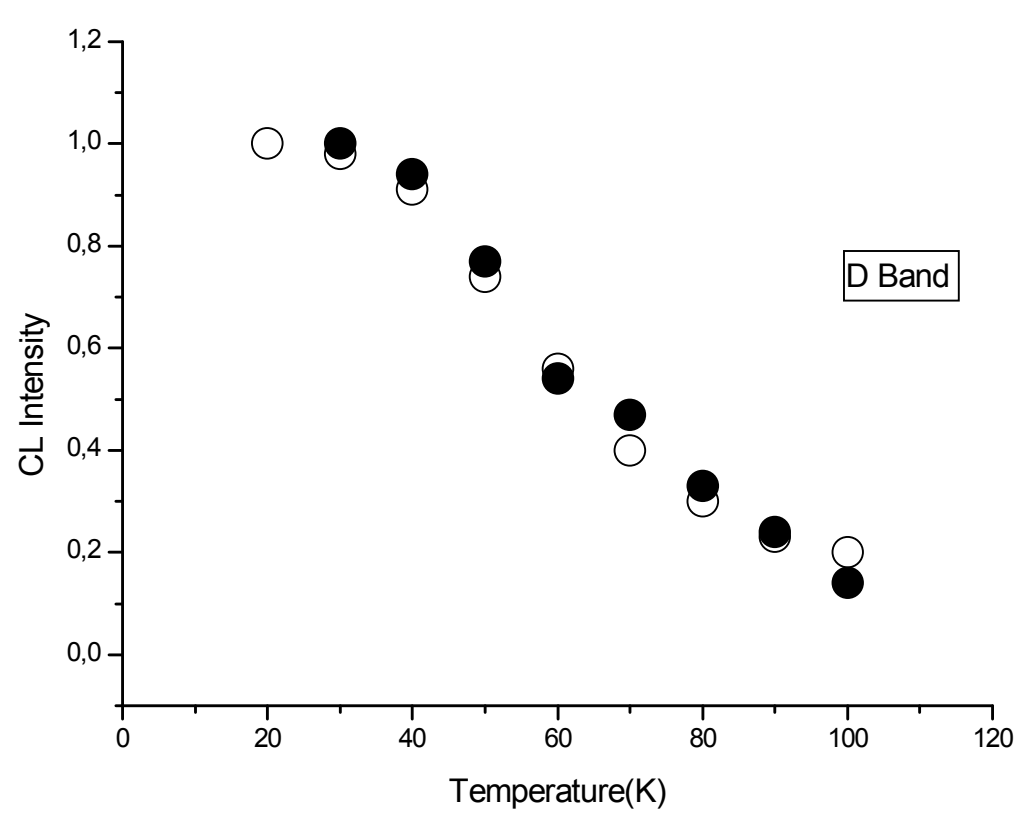

Fig. 11. CL Intensity versus temperature for $\mathrm{D}$ band( $\mathrm{Et}=0.5 \mathrm{eV})$ in $\mathrm{GaAs}: \mathrm{Si}$ (Lei,Leipner et al , 2004) Numerical results (•) Experimental data (०) (Djemel,Kouissa et al ,2009)

\section{Conclusion}

In this article we have shown the ability of the cathodoluminescence technique to study defects. We have demonstrated how this technique provides much data which are complementary in nature.

The quantitative study allows the knowledge of the interaction electron-matter in all aspect: energy dissipation of electron beam , generation function, penetration range , creation e-h pair energy, distribution of generated carriers and their concentration , comparison between the calculated CL intensity and the measured CL intensity ,determination of physics parameters of defects (defects density, energy levels in the band gap, the capture cross section ,recombination velocity ) and the parameters of carriers ( diffusion length).

The CL micrograph visualisation gives us a general cartography of the active defects and non-active defects.The measurements of luminescence band give valuable information on the energy levels associated to defects and their place in the band gap. The impact of electron beam irradiation allows to determine the thermal stability of the electronic properties of defects, to study the reactivity between defects and can identify the crystalline face ( impact different on $\mathrm{Zn}$ face and $\mathrm{O}$ face ). The measurements of CL intensity as a function of the temperature predict the evolution of many physical parameters with temperature. The comparison between the numerical results and the experimental data of $\mathrm{CL}$ intensity allows to extract the data on the radiative recombination centre. 


\section{References}

Bourgoin .J.C, Corbett .J.W, A new mechanism for interstitial migration, Phys. Letter A 38 , $1972,135-137$

Ben Naser.F, Matoussi.A ,Guermazi.S ,Fakhfakh.Z. Cathodoluminescence Investigation of GaAs thin layers , Physics Procedia 2,2009,827-833

Dierre.B,Yuan.X.L,Yao.Y.Z,Yokoyama.M ,Sekiguchi.T.J. Impact of electron beam irradiation on the cathodoluminescence intensity for $\mathrm{ZnO}$ and GaAs. Mater.Sci:Mater.Electron , 2008,S307-S310

Djemel.A . These de Doctorat d'Etat, Université Paris XI Orsay ,Dislocation dans GaAs et Propriétés électroniques par luminescence :Influence des impuretés, 1988

Djemel.A,Castaing.J,Visentin.N,Bonnet.M,Influence of thermal treatments on the electronic activity of dislocations in GaAs observed by cathodoluminescence Semicond.Sci.Technol.5,1990,1221-1224

Djemel.A,.Castaing.J,Chevallier.J,Henoc.P.Hydrogenation of GaAs covered by GaAlAs and subgrain boundary passivation,J.Phys.III,France 2,1992,2301-2307

Djemel.A, Tarento.R.J,Castaing.J,Marfaing.Y,Nouiri A, Electronic Surface Properties of GaAs in CL Experiments ,Phys.Stat.Sol.(a),1998,168,425-432

Djemel.A,Nouiri.A,,Tarento.R.J , Study of suface defects in GaAs by cathodoluminescence: calculation and experiment J.Phys.Condens.Mater 12,2000,10343-10347

Djemel.A,Nouiri.A,Kouissa.S,Tarento.R.J.Cathodoluminescence Calculation of n-GaAs. Surface Analysis and comparaison,Phys.Stat.Sol(a),2002,191, Nº1,223-229

Djemel.A, Nouiri.A,Kouissa.S, Tarento.R.J. Characterisation of n-GaAs by cathodoluminescence : Quantitative study and comparison,Current Issues on Multidisciplinary Microscopy Research and Education ,FORMATEX Microscopy Series N² Printed in Spain,2004,65-71

Djemel.A,Kouissa.S,Tarento.R.J,Temperature dependence of luminescence centre in cathodoluminescence ,Physics Procedia 2,2009,845-851

Everhart.T.E,Hoff.P.H, Determination of kilovolt electron energy dissipation vs penetration Distance in solid materials J.Appl.Phys.Vol.42,1,1971,5837-5846

Hergert.W,Reck.P,Passemann.L,Schreiber.J, Cathodoluminescence measurements using scanning electron microscope for the determination of semiconductors parameters Phys.Stat.Sol,(a),101,1987,661-618

Hergert.W, Hildebrandt.S, Pasemann.L Theoretical Investigations of Combined EBIC, LBIC, CL, and PL Experiments. The Information Depth of the PL Signal Phys.Stat.Sol,(a),102,1987,819-828

Hildebrandt.S, Schreiber.J, Hergert.W,I. Petrov.V.I Determination of the absorption coefficient and the internal luminescence spectrum of $\mathrm{GaAs}$ and $\mathrm{GaAs}_{1-x} \mathrm{P}_{x}(x$ $=0.375,0.78)$ from beam voltage dependent measurements of cathodoluminescence spectra in the scanning electron microscope. Phys.Stat.Sol,(a),110,1988,283-291

Jones.G.A.C,Nag.B.R,Gopinath.A,.Temperature variation of cathodoluminescence in direct gap semiconductors,Scanning Electron Microscopy (Part II)Proceeding of the worshop on electron specimen interaction :Theory for SEM IIT Research Institute ,1973,309-316

Lei.H,Leipner.H.S,Bondarenko.V,Schreiber.J.Identification of the $0.95 \mathrm{eV}$ luminescence band in n-GaAs:Si, J.Phys.Condens.Matter,16,2004,S279-S285 
Oualid.T,Singal.C.H,Dingas.J,Crest.J.P,Amzil.H,. Influence of illumination on the grain boundary recombination velocity in silicon J.Apl.Phys.55,1984,1195-1205

Phang.J.C.H,Pey.K.L,Chan.D.S.H. A simulation model for cathodoluminescence in the scanning electron microscope IEEE Trans.Electron.Devices,39,1992,782-791

Sauncy.T, Palsule.C.P, Holts.H, Gangopadhyay.S,. Lifetime studies of self-actived photoluminescence in heavily silicon-doped GaAs , Phys.Rev.B53,4,1996,1900-1906

Tarento.R.J,Marfaing.Y, Analysis of the recombination velocity and the electron beam induced current and cathodoluminescence contrasts at a dislocation, J.Appl.Phys.71,1992,4997-5003

William.E.W.Evidence for self-actived luminescence in GaAs:The Gallium Vacancy-Donor Centre ,Phys.Rev.168,3,1968,922-928

Wittry.D.B,Kyser.D.K. Measurement of diffusion lengths in direct Gap semiconductors by electron beam excitation ,J.Appl.Phys.Vol.38,1,1967,375-382

Wu.C.J,Wittry.D.B, Investigation of minority-carrier diffusion lengths by electron Bombardment of Schottky barriers.J.Appl.Phys.49,1978,2827-2836

Yacobi.B.G,Holt.D.B,Cathodoluminescence Microscopy of Inorganic Solids Plenium Press, 1990

Yacobi.B.G,Holt.D.B,Cathodoluminescence Scanning Electron Microscopy of semiconductors, J. Appl.Phys.59,4,,1986, R1-R24 


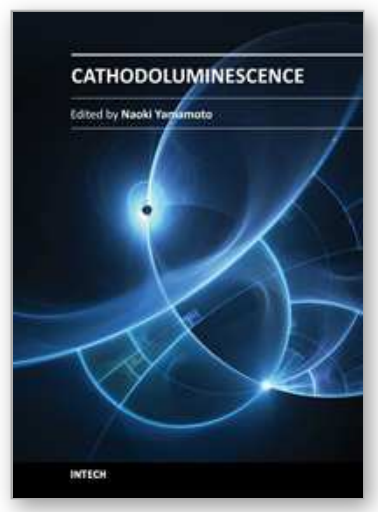

\author{
Cathodoluminescence \\ Edited by Dr. Naoki Yamamoto
}

ISBN 978-953-51-0362-2

Hard cover, 324 pages

Publisher InTech

Published online 28, March, 2012

Published in print edition March, 2012

Cathodoluminescence $(\mathrm{CL})$ is a non-destructive technique to characterize optical and electronic properties of nanostructures in many kinds of materials. Major subject is to investigate basic parameters in semiconductors, impurities in oxides and phase determination of minerals. CL gives information on carrier concentration, diffusion length and life time of minority carriers in semiconductors, and impurity concentration and phase composition in composite materials. This book involves 13 chapters to present the basics in the $\mathrm{CL}$ technique and applications to particles, thin films and nanostructures in semiconductors, oxides and minerals. The chapters covered in this book include recent development of $C L$ technique and applications to wide range of materials used in modern material science.

\title{
How to reference
}

In order to correctly reference this scholarly work, feel free to copy and paste the following:

A. Djemel and R-J. Tarento (2012). Study of Defects by Cathodoluminescence Measurements, Cathodoluminescence, Dr. Naoki Yamamoto (Ed.), ISBN: 978-953-51-0362-2, InTech, Available from: http://www.intechopen.com/books/cathodoluminescence/-study-of-defects-by-cathodoluminescencemeasurements-

\section{INTECH}

open science | open minds

\section{InTech Europe}

University Campus STeP Ri Slavka Krautzeka 83/A 51000 Rijeka, Croatia Phone: +385 (51) 770447 Fax: +385 (51) 686166 www.intechopen.com

\section{InTech China}

Unit 405, Office Block, Hotel Equatorial Shanghai No.65, Yan An Road (West), Shanghai, 200040, China 中国上海市延安西路65号上海国际贵都大饭店办公楼 405 单元 Phone: +86-21-62489820

Fax: +86-21-62489821 
(C) 2012 The Author(s). Licensee IntechOpen. This is an open access article distributed under the terms of the Creative Commons Attribution 3.0 License, which permits unrestricted use, distribution, and reproduction in any medium, provided the original work is properly cited. 